\title{
Role of Polyethylene Glycol in Screening the Common Bean (Phaseolus vulgaris L.) Cultivars for Root Traits under Water Stress Conditions
}

\author{
Asmat Ara ${ }^{1 *}$, P.A. Sofi ${ }^{1}$, M.A.Rather ${ }^{1}$, Z.A. Dar ${ }^{2}$, Showket Maqbool ${ }^{3}$ and Z.A. Baba ${ }^{4}$ \\ ${ }^{1}$ Division of Genetics and Plant Breeding, Wadura, Sopore, 193201 \\ ${ }^{2}$ Dryland Agriculture Research Station, Budgam \\ ${ }^{3}$ Division of Agri-Statistics, ${ }^{4}$ Division of Basic Sciences, Wadura, Sopore \\ *Corresponding author
}

\begin{abstract}
A B S T R A C T
Keywords

Genotype, PEG,

Water stress,

Variation

Article Info

Accepted:

20 June 2019

Available Online:

10 July 2019

Drought is increasingly becoming a serious challenge reducing common bean productivity. A study was conducted with the objective of evaluating common bean cultivars against different concentration levels of Polyethylene glycol which induces drought stress in radical length and root biomass to identify cultivars of common beans tolerant to drought stress and rank top performing accordingly. Complete Randomized Design with four replications and 50 treatments were employed in the laboratory experiment. Results showed that root biomass and radical length were maximum at control and decreased with an increase in PEG 6000 concentration.

\section{Introduction}

Drought can be simply defined as a period of below normal precipitation that limits plant productivity in a natural or agricultural system. In the field, drought can cause a number of plant stresses including temperature, light and nutrient stresses. However, the stress component that defines drought is a decrease in the availability of soil water. This decreased water availability can be quantified as a decrease in water potential (Kramer and Boyer, 1995). Decreased water potential (decreased free energy of the water)

makes it more difficult for the plant to take up water and this in turn elicits a range of responses that allow the plant to avoid water loss, allow water uptake to continue at reduced water potential or allow the plant to tolerate reduced tissue water content. The physiological mechanisms involved in cellular and whole plant responses to water stress therefore generate considerable interest and are frequently reviewed (Smith and Griffiths, 1993). It therefore, appears that drought stress is a worldwide production constraint for common bean productivity. Some management practices can contribute to
\end{abstract}


the increase of common bean yield under drought conditions, thus the identification and selection of tolerant cultivars becomes an efficient and economical production strategy. Drought tolerance implies the ability to sustain substantial yield under moderate water stress and not the ability to survive over prolonged and severe water stress periods (Ashraf, 2005). Water stress has been reported to reduce the expression of many characteristics in beans except days to flowering and moisture retention in the leaf (Farooq, 2006). In common beans, accelerated maturity of crop along with reducing grain yield and mean weight of hundred seeds following water stress have been reported (Hufsteler et al., 2007). There is a wide variation among cultivars of common beans in terms of tolerance to drought. Some cultivars respond negatively to drought and give low yield while others give substantial yield. The ones that perform better and give a reasonable yield are selected, multiplied and included in the breeding programmes. Various methods have been employed to identify drought tolerant genotypes and efforts have been made in the past to screen bean varieties which differed in drought tolerance (George et al, 2013). Polyethylene glycol (PEG) compounds have been used to induce osmotic stress in petri dish (in vitro) for plants to maintain uniform water potential during the experimental period. PEG has been used often as water stress inducer in many studies to screen drought tolerant germplasm (Turkan et al, 2005). PEG is a polymer and considered as better chemical than others to induce water stress artificially (Kaur et al, 1998; Ashraf and Iram, 2005).

\section{Materials and Methods}

Laboratory experiment was conducted at Division of Genetics and Plant Breeding Faculty of Agriculture, Wadura. Experimental material consisted of 50 genotypes including two checks SR-1 and SFB-1. Completely randomized design with three replications was used to investigate the effects of PEG induced water stress on germination and seedling growth of common bean cultivars.

\section{Procedure}

Fifty different accessions of beans were evaluated for water stress tolerance. Water stress was simulated by non-ionic water soluble polymer polyethylene glycol of molecular weight 6000. Solution of PEG6000 having osmotic potential of -1.0 bar as described by Michel and Kaufiman (1973) was prepared by dissolving different concentrations of PEG (20,10 and $0 \mathrm{~g}$ ) in $1000 \mathrm{ml}$ of distilled water. For control conditions, distilled water was used. Screening of these cultivars was done by allowing them to grow for 14 days under different PEG-6000 concentration. After 14 days, data were recorded for root biomass and radical length under control as well as water stress conditions. Seeds of different cultivars were surface-sterilized with $0.1 \%$ Sodium hypochlorite $(\mathrm{w} / \mathrm{v})$ for 2 minutes. Four sterilized seeds of each cultivar were spread over a blotting paper in a petri-dish separately. Two different concentrations of PEG that were mentioned previously were added in different petri dishes every day. The whole set were placed in the growth chamber with bright diffused light, $70-80 \%$ relative humidity and $25-30^{\circ} \mathrm{C}$ temperature.

\section{Results and Discussion}

The radical length under controlled conditions had mean value of 6.168 with highest value in WB-83 (9.5) followed by WB-5176 (9.42) and WB-451 (9.21) and lowest in WB-448-1 (3.35). On treatment with $10 \%$ PEG it was had mean value of 3.638 with highest value in WB-216 (5.40) followed by WB-901 (5.25) 
and WB-5176(5.12) and lowest in WB-25575 (2.06). On treatment with PEG 20\% radical length had mean value of 1.840 with highest value in WB-216 (4.65) followed by WB451(2.9) and WB-5176(2.85) and lowest in WB-6960(1.01). Under controlled conditions root biomass had a mean value of 0.275 with highest value in WB-451 (0.540) followed by WB-9414 (0.481) and WB-216 (0.479) and lowest value was found in WB- 25575(0.092).
On treatment with $10 \%$ PEG, root biomass had mean value of 0.152 with highest value in WB-216 (0.327) followed by WB-435 (0.3) and WB-966 (0.2) while as it was lowest in WB-25575 (0.047). On treatment with 20\% PEG root biomass had mean value of 0.009 with highest value in WB-206 (0.027) followed by WB-185 (0.017) and WB-956 $(0.013)$ and lowest in WB-901 (0.004).

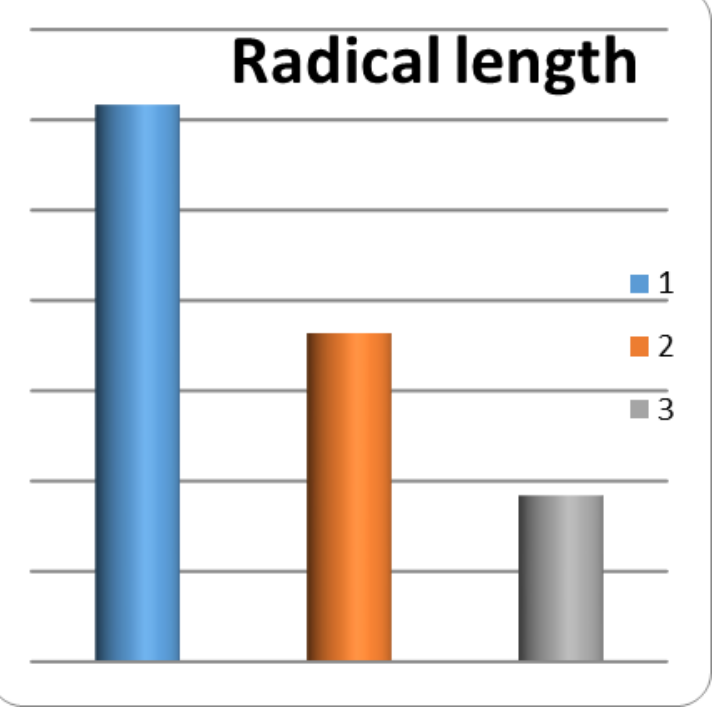

conditions. PEG was used by many researchers in inducing drought in seeds and seedling to simulate conditions that exist in the field under dry soil conditions or drought (Heikal and Shaddad, 1982; Kuhad et al., 1987). Turhum (1997) emphasised that PEG caused osmotic stress and could be used as a drought inducer. Similar results were obtained by Smok et al., (1993) and $\mathrm{Hu}$ and Jones (2004) who used PEG to induced osmotic stress on germinating seed and seedlings of cotton, peas, wheat, beans and sorghum. Seedling growth parameters measured such as fresh weight, dry weight and length of plumule and radicle also decreased as the concentration PEG increased. This implied that the water available to the seedlings became scarce as the PEG concentration increased (Fig. 1-4 and Table 1). 
Table.1 In-vitro response of common bean (Phaseolus vulgaris L.) genotypes to different levels of PEG 6000

\begin{tabular}{|c|c|c|c|c|c|c|}
\hline Genotype & & iomass (g) & & & cal length (c & \\
\hline & control & $10 \%$ PEG & 20\% PEG & Control & $10 \%$ PEG & $20 \%$ PEG \\
\hline WB-6 & 0.148 & 0.127 & 0.006 & 6.84 & 3.82 & 2.11 \\
\hline WB-22 & 0.238 & 0.156 & 0.004 & 5.15 & 4.45 & 2.50 \\
\hline WB-48 & 0.250 & 0.126 & 0.011 & 5.28 & 3.60 & 2.30 \\
\hline WB-83 & 0.350 & 0.123 & 0.013 & 9.50 & 4.15 & 2.05 \\
\hline WB-112 & 0.250 & 0.185 & 0.006 & 6.65 & 4.00 & 2.06 \\
\hline WB-115 & 0.206 & 0.119 & 0.010 & 4.10 & 3.21 & 1.21 \\
\hline WB-185 & 0.476 & 0.223 & 0.017 & 5.24 & 3.35 & 1.25 \\
\hline WB-195 & 0.218 & 0.101 & 0.004 & 6.0 & 4.07 & 2.3 \\
\hline WB-206 & 0.360 & 0.198 & 0.027 & 5.2 & 3.5 & 1.08 \\
\hline WB-216 & 0.479 & 0.327 & 0.012 & 8.4 & 5.4 & 4.65 \\
\hline WB-222 & 0.273 & 0.167 & 0.008 & 5.1 & 2.15 & 1.90 \\
\hline WB-257 & 0.142 & 0.105 & 0.006 & 5.43 & 4.12 & 2.65 \\
\hline WB-258 & 0.230 & 0.110 & 0.008 & 4.76 & 2.55 & 1.61 \\
\hline WB-335 & 0.222 & 0.111 & 0.012 & 5.95 & 4.750 & 2.5 \\
\hline WB-341 & 0.139 & 0.096 & 0.011 & 4.23 & 3.15 & 1.28 \\
\hline WB-401 & 0.282 & 0.084 & 0.009 & 5.58 & 4.63 & 2.35 \\
\hline WB-435 & 0.125 & 0.300 & 0.007 & 4.15 & 3.22 & 1.89 \\
\hline WB-448-1 & 0.202 & 0.121 & 0.005 & 3.35 & 2.4 & 1.52 \\
\hline WB-451 & 0.541 & 0.240 & 0.013 & 9.21 & 4.45 & 2.9 \\
\hline WB-489 & 0.247 & 0.114 & 0.006 & 6.54 & 3.14 & 1.23 \\
\hline WB-565 & 0.160 & 0.123 & 0.009 & 4.05 & 2.500 & 1.11 \\
\hline WB-630 & 0.355 & 0.162 & 0.011 & 5.17 & 3.45 & 1.8 \\
\hline WB-651 & 0.172 & 0.076 & 0.008 & 4.28 & 2.70 & 1.31 \\
\hline WB-662 & 0.354 & 0.117 & 0.010 & 4.50 & 2.15 & 1.04 \\
\hline WB-665 & 0.113 & 0.172 & 0.005 & 6.15 & 3.3 & 1.33 \\
\hline WB-832 & 0.381 & 0.137 & 0.012 & 6.1 & 3.5 & 2.15 \\
\hline WB-901 & 0.460 & 0.138 & 0.004 & 7.13 & 5.25 & 2.24 \\
\hline WB-952 & 0.154 & 0.096 & 0.008 & 7.02 & 4.16 & 1.45 \\
\hline WB-956 & 0.360 & 0.132 & 0.013 & 8.9 & 4.500 & 1.24 \\
\hline WB-966 & 0.402 & 0.211 & 0.005 & 4.9 & 2.43 & 1.36 \\
\hline WB-967 & 0.215 & 0.114 & 0.006 & 5.19 & 3.27 & 1.15 \\
\hline WB-969 & 0.250 & 0.112 & 0.010 & 5.88 & 3.11 & 1.91 \\
\hline WB-1282 & 0.337 & 0.129 & 0.010 & 6.65 & 3.23 & 1.28 \\
\hline WB-1304 & 0.270 & 0.162 & 0.009 & 4.4 & 3.1 & 1.5 \\
\hline WB-1319 & 0.096 & 0.079 & 0.007 & 7.21 & 4.75 & 2.33 \\
\hline WB-1492 & 0.318 & 0.131 & 0.008 & 7.5 & 3.22 & 1.51 \\
\hline WB-1587 & 0.185 & 0.163 & 0.008 & 5.75 & 3.26 & 1.03 \\
\hline WB-1634 & 0.098 & 0.054 & 0.009 & 7.3 & 4.44 & 1.37 \\
\hline
\end{tabular}


Int.J.Curr.Microbiol.App.Sci (2019) 8(7): 2776-2782

\begin{tabular}{|c|c|c|c|c|c|c|}
\hline WB-1643 & 0.247 & 0.107 & 0.009 & 7.26 & 3.47 & 1.72 \\
\hline WB-1644 & 0.312 & 0.226 & 0.010 & 9.03 & 4.14 & 2.25 \\
\hline WB-1664 & 0.201 & 0.090 & 0.012 & 8.95 & 5.01 & 2.01 \\
\hline WB-3629 & 0.388 & 0.213 & 0.008 & 5.66 & 3.05 & 2.17 \\
\hline WB-4564 & 0.360 & 0.176 & 0.010 & 6.29 & 4.15 & 1.26 \\
\hline WB-5176 & 0.250 & 0.125 & 0.006 & 9.42 & 5.12 & 2.85 \\
\hline WB-6960 & 0.319 & 0.147 & 0.008 & 6.15 & 3.35 & 1.01 \\
\hline WB-9414 & 0.481 & 0.333 & 0.012 & 4.18 & 2.85 & 1.72 \\
\hline WB-25575 & 0.092 & 0.047 & 0.009 & 5.26 & 2.06 & 1.21 \\
\hline WB-285575 & 0.289 & 0.106 & 0.009 & 6.67 & 4.14 & 2.7 \\
\hline SFB-1 & 0.403 & 0.126 & 0.008 & 7.34 & 3.53 & 2.14 \\
\hline SR-1 & 0.374 & 0.144 & 0.011 & 7.45 & 4.62 & 2.52 \\
\hline Mean & 0.275 & 0.153 & 0.009 & 6.618 & 3.638 & 1.840 \\
\hline C.D (p<0.05) & \multicolumn{2}{|c|}{ Genotype $=3.963$} \\
\end{tabular}

Fig.1 Radical length growth at control, $10 \%$ and 20\% in WB-216

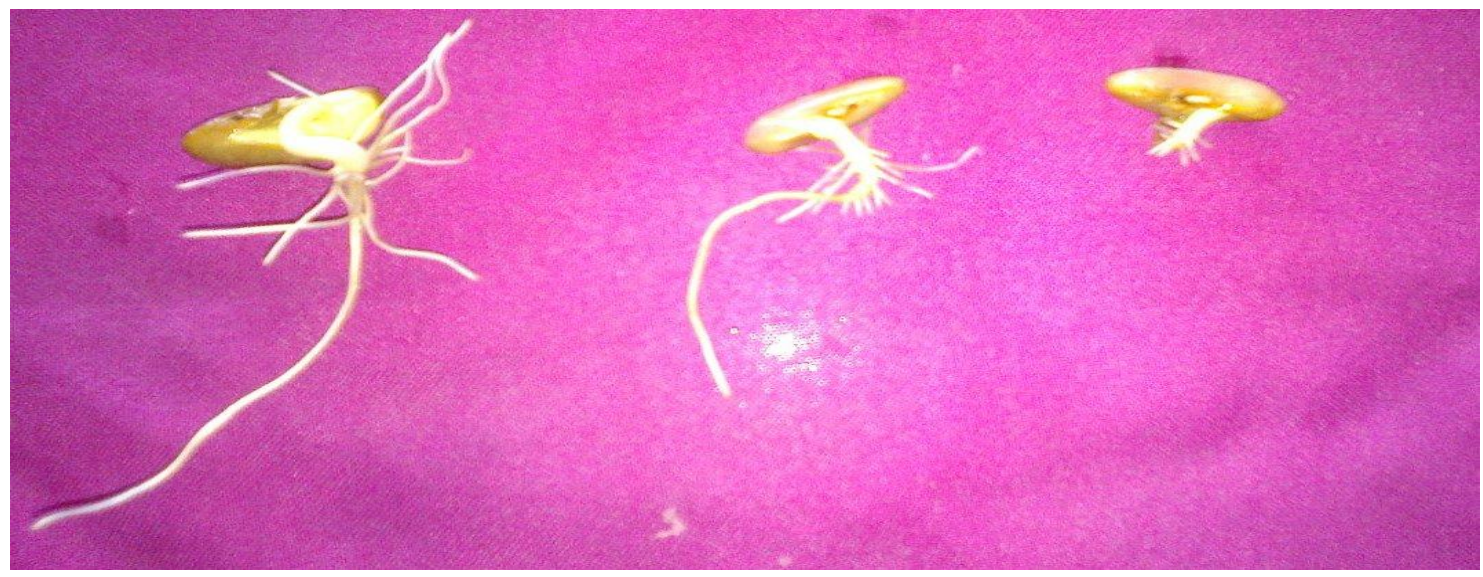

Fig.2 Radical length growth at control, $10 \%$ and $20 \%$ in WB-83




Fig.3 Box plots showing variation in genotypes around the mean for root biomass
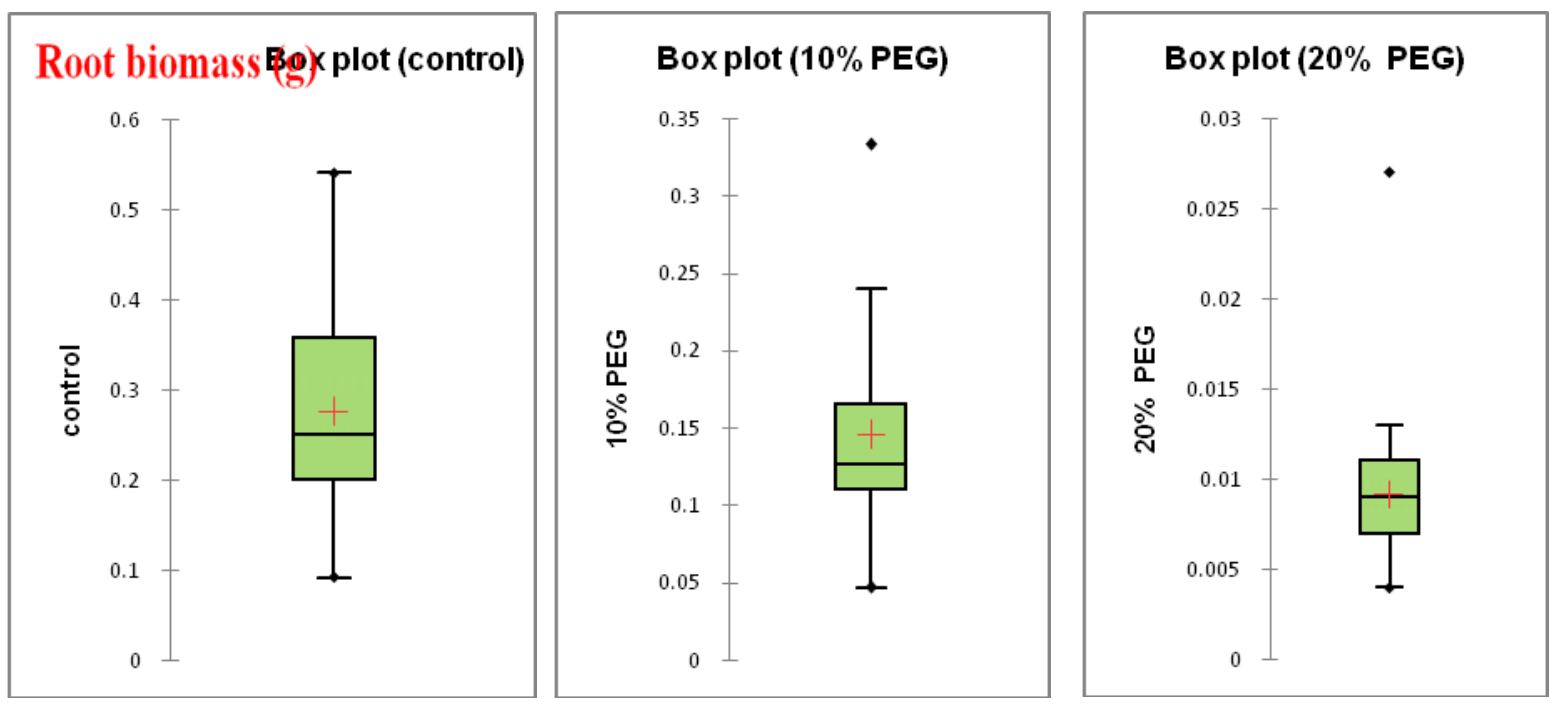

Fig.4 Box plots showing variation in genotypes around the mean for radical length

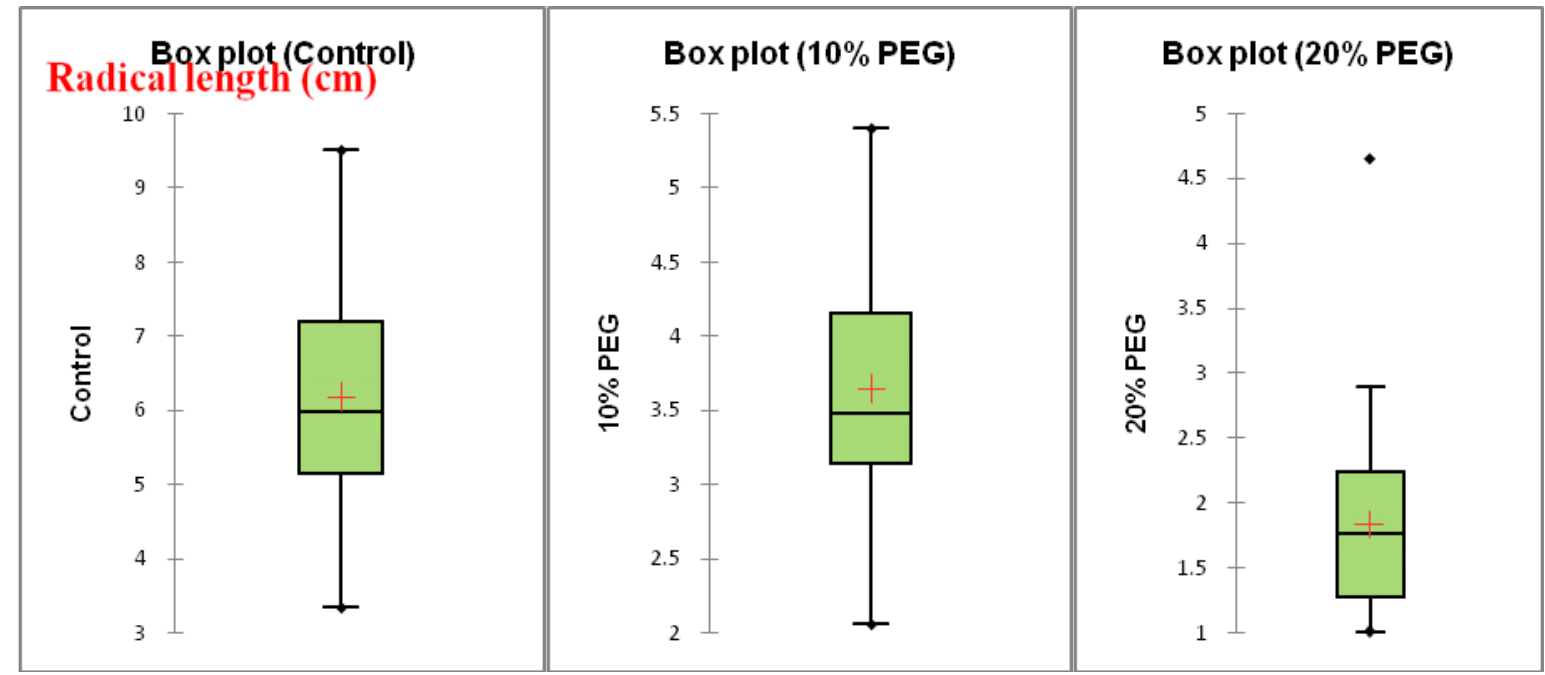

PEG absorbed more water since it had high osmotic potential. Osmotic stress delayed the emergence of both radicle and further development of seedling. These results were comparable with the findings of Turhum (1997). They indicated that decline in the seedling development was due to osmotic potential of PEG or ionic effects or a combination of both.

In conclusion, cultivars of common beans showed a highly significant difference in relation to induce water deficit stress. Different concentrations of PEG created highly significant different environments for common bean cultivars concentration also created highly significant different environment in which seed germinated and seedlings grew.

\section{References}

Ashraf, M. and A. Iram. 2005. Drought stress induced changes in some organic 
substances in nodules and other plant parts of two potential legumes differing in salt tolerance. Flora 200: 535-546

Farooq, U and A. Bano. 2006. Effect of abscisic acid and chlorocholine chloride on nodulation and biochemical content of Vigna radiata L. under water stress. Pak J Bot. 38(5):1511-1518

George, S., Jatoi, S.A and S.U. Siddiqui. (2013). Genotypic differences against PEG simulated Drought Stress in Tomato. Pak. J. Bot., 45: 1551-1556.

Heikal, M.M.D. and A.M.A. Shaded. 1982. Alleviation and separation of osmotic stress on seed germination and seedling growth of cotton, pea and wheat by praline. Australian Phytology. 22:433444

Hufsteler, E.V, Boerma, H.R, Carter, T.E and H.J. Earl. 2007. Genotypic variation for three physiological traits affecting drought tolerance in soybean. Crop Sci. 47: 25-35. http://dx.doi.org/10.2135/ cropsci2006.04.0243.

Kaur, S. Gupta, A.K and Kaur, N. (1998). Gibberellic acid and kinetin partially reverse the effect of water stress on germination and seedling growth in chickpea. Plant Growth Regul., 25: 2933.

Kramer, P.J. and J.S. Boyer, 1995. Water Relations of Plants and Soils. 1st Edn., Academic Press, San Diego, New York, USA., pp: 491-495.

Kuhad, M.S., I.S. Sheoran and
S.Kumari.1987. Alleviation on osmotic stress on seed germination and ionic effect during germination and early seedling growth in pearl millet by presoaking the seeds with growth regulators. Indian journal of Plant Physiology. 30:139-143.

Michel B.E. and Kaufmann M.R. 1973. The osmotic potential of polyethylene glycol 6000. Plant Physiol. 51:914-917.

Smith, J.A.C. and H. Griffiths, 1993. Water Deficits: Plant Responses from Cell to Community. Bios Scientific Publishers, UK., pp: 331-332.

Smok. M. A., M. Chojnowski, F. Corbineau and D. Come. 1993. Effects of osmotic treatments on sunflower seed germination in relation with temperature and oxygen. In: Proceedings of 4th International Workshop on seed: Basic and Applied Aspects of Seed Biology. (Eds.): D. Come and F. Corbineau. Angers, France, pp. 1033-1038

Turhan, H. 1997. Salinity studies in potatoes (Solanum tuberosum L.). PhD. Thesis. The University of Reading, UK. Pp247.

Turkan, I., M. Bor, F. Zdemir and H. Koca. 2005. Differential responses of lipid peroxidation and antioxidants in the leaves of drought-tolerant $P$. acutifolius and drought-sensitive $P$. vulgaris subjected to polyethylene glycol mediated water stress. Plant Sci. 168: 223-231.

\section{How to cite this article:}

Asmat Ara, P.A. Sofi, M.A.Rather, Z.A. Dar, Showket Maqbool and Baba, Z.A. 2019. Role of Polyethylene Glycol in Screening the Common Bean (Phaseolus vulgaris L.) Cultivars for Root Traits under Water Stress Conditions. Int.J.Curr.Microbiol.App.Sci. 8(07): 2776-2782. doi: https://doi.org/10.20546/ijcmas.2019.807.339 